\title{
Efficacy of High-Dose Albendazole with Ivermectin for Treating Imported Loiasis, Italy
}

\author{
Federico Gobbi, Dora Buonfrate, \\ Francesca Tamarozzi, Monica Degani, \\ Andrea Angheben, Zeno Bisoffi
}

We describe the outcomes of 16 cases of imported loiasis in Italy. Patients had microfilaremia $<20,000 / \mathrm{mL}$ and were treated with high-dose albendazole for 28 days and a single dose of ivermectin. This combination might be an effective treatment option in nonendemic areas, when diethylcarbamazine, the drug of choice, is not available.

$L$ oa loa is a filarial nematode transmitted by tabanid flies of the genus Chrysops, which inhabits forested areas of West and Central Africa (1). It is estimated that $>10$ million people are infected with this parasite (2). Adult worms move under the skin or in the intermuscular fascia and can produce microfilariae. Loiasis can cause a wide range of symptoms, most frequently migrant edemas (Calabar swellings). Severe neurologic complications have also been reported (2). A retrospective study showed increased mortality rates in patients with high microfilaremia (3), indicating that this infection is not a benign condition, as previously thought.

Three drugs are currently used to treat loiasis: diethylcarbamazine, ivermectin, and albendazole (4). Diethylcarbamazine is preferred but is usually unavailable outside of specific World Health Organization mass drug administration programs. In addition, multiple courses of diethylcarbamazine are often required to achieve a clinical and parasitological cure (5), and the drug should not be used in patients with high microfilaremia levels because of the risk of encephalopathy (4). Trials in loiasisendemic countries showed that short courses of albendazole had little effect on L. loa infection $(6,7)$, but longer treatments $(200 \mathrm{mg} 2 \times / \mathrm{d}$ for $21 \mathrm{~d})$ resulted in decreased microfilaremia, blood eosinophil levels, and antifilarial antibodies (8). In 2018, a patient with high microfilaremia was reported to be clear of infection after four 21day courses of albendazole at a dose of $400 \mathrm{mg}$ daily,

Author affiliations: IRCCS Sacro Cuore Don Calabria Hospital, Negrar di Valpolicella, Italy (F. Gobbi, D. Buonfrate, F. Tamarozzi, M. Degani, A. Angheben, Z. Bisoffi); ISS (Istituto Superiore Sanità), Rome, Italy (F. Tamarozzi); Università degli Studi di Verona, Verona, Italy (Z. Bisoffi)

DOI: https://doi.org/10.3201/eid2508.190011 followed by a single $150 \mu \mathrm{g} / \mathrm{kg}$ dose of ivermectin (9). We describe the outcomes of 16 cases of imported loiasis in Italy with high-dose albendazole for 28 days and a single dose of ivermectin.

\section{The Study}

The reference Ethics Committee (Comitato Etico per la Sperimentazione Clinica delle Province di Verona e Rovigo) approved this study in July 2016 (study protocol no. 33908). We reviewed the medical records of patients with loiasis admitted to IRCCS Sacro Cuore Don Calabria Hospital (Negrar di Valpolicella, Italy) during 1993-2016 who had been treated with albendazole ( $400 \mathrm{mg} 2 \times / \mathrm{d}$ for 28 days), followed by ivermectin $(200 \mu \mathrm{g} / \mathrm{kg}$, in single or multiple doses). For study purposes, we defined a case of loiasis by having previously stayed in an endemic country plus meeting $\geq 1$ of 3 criteria: 1) eyeworm observed in the eye conjunctiva within the previous 2 months; 2) detection of $L$. loa microfilariae in the peripheral blood, determined by the leukoconcentration method (processing $13 \mathrm{~mL}$ of venous blood, with density assessed by examining Giemsa-stained thick smears, prepared with $100 \mu \mathrm{L}$ of blood); or 3) Calabar swellings associated with eosinophilia ( $>500$ eosinophils $/ \mu \mathrm{L})$ within the previous 2 months. In addition, only patients with $\geq 12$ months of follow-up were included.

A total of 23 patients were considered eligible for inclusion. We excluded 7 of them because they had $<12$ months of follow-up. We included the remaining 16 patients (6 migrants and 10 expatriates) in the analysis (Table). Eleven patients had L. loa microfilariae in their blood; 5 had Calabar swellings and eosinophilia; none had an observed eyeworm. Of note, all 6 migrants had eosinophil counts of $500-1,500 / \mu \mathrm{L}$, whereas all expatriates had eosinophil counts $>1,500 / \mu \mathrm{L}$, in line with previous observations (10).

A commercial ELISA test, based on Acanthocheilonema vitae as source of antigens (Bordier Affinity Products, http://www.bordier.ch), returned positive results for all patients. We also evaluated serologic results retrospectively for patients diagnosed before 2014. Liver function (alanine transaminase and aspartate transaminase levels) had been checked after $\approx 2$ weeks from the onset of treatment with albendazole; no changes were observed in any patient. We recommended that blood tests be repeated every 2 months until patients were free of microfilaremia 
Table 1. Clinical and laboratory characteristics of 16 patients with imported loiasis treated with albendazole and ivermectin, Italy, 1993-2016*

\begin{tabular}{|c|c|c|c|c|c|c|c|c|c|c|c|}
\hline $\begin{array}{l}\mathrm{Pt} \\
\text { no. }\end{array}$ & $\begin{array}{l}\text { Age, } \\
\text { y/sex }\end{array}$ & Status & $\begin{array}{l}\text { Place of } \\
\text { infection }\end{array}$ & $\begin{array}{c}\text { Year of } \\
\text { diagnosis }\end{array}$ & $\begin{array}{l}\text { Calabar } \\
\text { swelling }\end{array}$ & $\mathrm{EOS} / \mu \mathrm{L}$ & $\begin{array}{l}\text { Antifilarial } \\
\text { antibodies, } \\
\text { OD* }^{*}\end{array}$ & $\begin{array}{l}\text { MFF/ } \\
\mathrm{mL}\end{array}$ & Co-infections & $\begin{array}{c}\text { Other } \\
\text { treatments }\end{array}$ & $\begin{array}{l}\text { Follow- } \\
\text { up } \\
\text { period }\end{array}$ \\
\hline 1 & $64 / \mathrm{M}$ & $\mathrm{E}$ & CAR & 2005 & Yes & 4,650 & 5.06 & Neg & $\begin{array}{c}\text { Giardiasis, } \\
\text { strongyloidiasis }\end{array}$ & Tinidazole & $12 \mathrm{y}$ \\
\hline 2 & $28 / F$ & $E$ & Gabon & 2008 & Yes & 3,300 & 4.79 & $\mathrm{Neg}$ & None & None & $10 y$ \\
\hline 3 & $56 / \mathrm{M}$ & $\mathrm{E}$ & Chad & 2008 & No & 4,500 & 4.22 & 270 & Amebiasis & $\begin{array}{l}\text { Tinidazole, } \\
\text { paromomycin }\end{array}$ & $4 y$ \\
\hline 4 & $28 / F$ & $\mathrm{M}$ & Angola & 2010 & No & 790 & None & 263 & None & None & $14 \mathrm{mo}$ \\
\hline 5 & $58 / \mathrm{M}$ & $\mathrm{E}$ & CAR & 2010 & Yes & 9,320 & 1.74 & Neg & None & None & $8 \mathrm{y}$ \\
\hline 6 & $52 / \mathrm{M}$ & $E$ & Cameroon & 2010 & Yes & 2,940 & 5.10 & 1 & None & None & $8 \mathrm{y}$ \\
\hline 7 & $55 / \mathrm{M}$ & $E$ & DRC & 2011 & Yes & 2,040 & 5.21 & 9 & None & None & $7 y$ \\
\hline 8 & $49 / \mathrm{M}$ & $E$ & Congo & 2014 & Yes & 4,930 & 4.31 & $\mathrm{Neg}$ & None & None & $4 y$ \\
\hline 9 & $67 / F$ & $E$ & Nigeria & 2014 & Yes & 13,100 & 4.05 & Neg & $\begin{array}{l}\text { Schistosomiasis, } \\
\text { strongyloidiasis }\end{array}$ & Praziquantel & $4 y$ \\
\hline 10 & 69/M & $\mathrm{E}$ & Cameroon & 2015 & Yes & 1,620 & 2.19 & 152 & None & None & $3 y$ \\
\hline $11 \dagger$ & $24 / \mathrm{M}$ & $\mathrm{M}$ & Nigeria & 2015 & No & 1,300 & 2.16 & 160 & $\begin{array}{l}\text { Hookworm, } \\
\text { latent } \\
\text { tuberculosis }\end{array}$ & DEC & $26 \mathrm{mo}$ \\
\hline $12 \ddagger$ & $27 / \mathrm{M}$ & $\mathrm{M}$ & Cameroon & 2015 & No & 700 & 1.53 & 491 & $\begin{array}{c}\text { Hookworm, } \\
\text { schistosomiasis }\end{array}$ & Praziquantel & $26 \mathrm{mo}$ \\
\hline 13 & $75 / \mathrm{M}$ & $\mathrm{E}$ & Cameroon & 2015 & Yes & 4,100 & 2.85 & Neg & None & None & $18 \mathrm{mo}$ \\
\hline 14 & $29 / \mathrm{M}$ & $\mathrm{M}$ & Cameroon & 2016 & No & 590 & 2.85 & 990 & $\begin{array}{c}\text { Hookworm, } \\
\text { schistosomiasis, } \\
\text { HMS }\end{array}$ & $\begin{array}{l}\text { Praziquantel, } \\
\text { atovaquone/ } \\
\text { proguanile }\end{array}$ & $19 \mathrm{mo}$ \\
\hline 15 & $22 / \mathrm{M}$ & $\mathrm{M}$ & Cameroon & 2016 & No & 500 & 1.39 & 9,800 & $\begin{array}{l}\text { Schistosomiasis, } \\
\text { Mansonellosis } \\
\text { perstans, chronic } \\
\text { HBV }\end{array}$ & $\begin{array}{l}\text { Praziquantel, } \\
\text { mebendazole }\end{array}$ & $18 \mathrm{mo}$ \\
\hline 16 & 18/M & $\mathrm{M}$ & Nigeria & 2016 & No & 1,200 & 2.52 & 477 & Hookworm & None & $16 \mathrm{mo}$ \\
\hline \multicolumn{12}{|c|}{$\begin{array}{l}\text { *CAR, Central African Republic; DEC, diethylcarbamazine; DRC, Democratic Republic of the Congo; E, expatriate; EOS, eosinophils; HBV, hepatitis B } \\
\text { virus; HMS, hyperreactive malarial splenomegaly; M, migrant; MFF, microfilariae; Neg, negative; OD, optical density; Pos, positive; Pt, patient. } \\
{ }^{*} \text { OD test is positive at } \geq 1 \text { s. } \\
\text { †Patient with failure of albendazole and ivermectin treatment. } \\
\text { †Received } 1 \text { additional course of ivermectin. }\end{array}$} \\
\hline
\end{tabular}

and that patients make annual follow-up visits for 4-5 years. However, these recommendations were seldom followed, and follow-up visits had to be tailored to each patient's characteristics and needs. One patient received a further course of ivermectin due to the persistence of low-level microfilaremia 4 months after treatment; testing at subsequent follow-up visits showed no microfilaremia. No severe adverse events were reported, although 2 patients reported itching.

Posttreatment follow-up periods ranged from 14 months to 12 years. Within 6 months after the end of the treatment, 15 (93.8\%) of 16 patients had recovered completely, as demonstrated by disappearance of symptoms, normalization of eosinophil counts, and negative microfilaremia. The remaining patient reported presence of Calabar swelling and microfilaremia 1 month after treatment, so he received a single course of diethylcarbamazine, after which symptoms disappeared within 2 months.

\section{Conclusions}

Our retrospective study indicates that using the combination of albendazole and ivermectin resulted in a high rate of recovery $(15 / 16,93.8 \%)$ in patients with loiasis with microfilaremia $<20,000 / \mathrm{mL}$. By comparison, a study by Klion et al. found that only $38 \%$ of 32 patients treated with diethylcarbamazine were cured after 1 course of therapy, and some patients continued to be symptomatic despite $>4$ courses of treatment (5). Three of these symptomatic patients, unresponsive to diethylcarbamazine, were administered albendazole (200 mg $2 \times / \mathrm{d}$ for $21 \mathrm{~d})$ and then recovered (8). Moreover, Klion et al. performed a double-blind, placebocontrolled trial to assess the filaricidal activity and clinical safety of albendazole at the $200 \mathrm{mg}$ dosage (11). Within 6 months, albendazole treatment reduced microfilaremia substantially, although not completely. After 6 months, microfilarial density was at $20 \%$ of pretreatment level in the albendazole treatment group compared with $84.8 \%$ in the 
placebo group. Ivermectin has been administered alone only to substantially reduce microfilaremia levels, not as a cure, because macrofilaricidal action was not demonstrated $(12,13)$. It was on the basis of these earlier reports, and because of the unavailability of diethylcarbamazine in Italy, that in 2004 we decided to treat our loiasis patients with a regimen of albendazole at a higher dosage $(400 \mathrm{mg} 2 \times / \mathrm{d})$ for a longer period ( $28 \mathrm{~d}$ ), followed by a single dose of ivermectin $(200 \mu \mathrm{g} / \mathrm{kg})(14)$.

The main limitations of this study are the retrospective design and the low number of patients included. Moreover, only 1 patient had a microfilaremia level of $\approx 10,000$ / $\mathrm{mL}$; however, this level was still lower than the threshold of $20,000 / \mathrm{mL}$ established by Kamgno et al. to avoid severe adverse events (15). Hence, in our patients, ivermectin could have been administered safely before albendazole. However, we cannot recommend this treatment schedule for patients with microfilaremia $>20,000 / \mathrm{mL}$.

Because data are scant, additional information about the treatment and outcome of loiasis imported into nonendemic countries is useful for clinicians. A previous study pointed out wide heterogeneity of treatment strategies for imported loiasis (16), highlighting the need for guidelines for treating loiasis in nonendemic areas, where there is no risk of reinfection.

In conclusion, a combination of high-dose albendazole (400 mg $2 \times / \mathrm{d}$ for $28 \mathrm{~d}$ ) plus a single $200 \mu \mathrm{g} / \mathrm{kg}$ dose of ivermectin might be recommended for loiasis patients with microfilaremia $<20,000 / \mathrm{mL}$ as an alternative to diethylcarbamazine, which is the treatment of choice for loiasis but is often unavailable. In case of clinical cure (absence of symptoms) but persistence of low levels of microfilaremia, an option might be a second course of ivermectin to achieve clearance of microfilariae ( 9 ).

Funding for this work was provided by the Italian Ministry of Health "Fondi Ricerca Corrente - Linea 3, progetto 8" to IRCCS Sacro Cuore Don Calabria Hospital.

\section{About the Author}

Dr. Gobbi is a specialist in infectious diseases at the Centre for Tropical Diseases of Negrar, Verona, Italy. His main research interests focus on schistosomiasis, loiasis, mansonellosis, malaria, and arbovirosis surveillance.

\section{References}

1. Boussinesq M. Loiasis. Ann Trop Med Parasitol. 2006;100:715-31. http://dx.doi.org/10.1179/136485906X112194

2. Metzger WG, Mordmuller B. Loa loa - does it deserve to be neglected? Lancet Infect Dis. 2014;14:353-7.

3. Chesnais CB, Takougang I, Paguélé M, Pion SD, Boussinesq M. Excess mortality associated with loiasis: a retrospective population- based cohort study. Lancet Infect Dis. 2017;17:108-16. http://dx.doi.org/10.1016/S1473-3099(16)30405-4

4. Boussinesq M. Loiasis: new epidemiologic insights and proposed treatment strategy. J Travel Med. 2012;19:140-3. http://dx.doi.org/ 10.1111/j.1708-8305.2012.00605.x

5. Klion AD, Ottesen EA, Nutman TB. Effectiveness of diethylcarbamazine in treating loiasis acquired by expatriate visitors to endemic regions: long-term follow-up. J Infect Dis. 1994;169:604-10. http://dx.doi.org/10.1093/infdis/169.3.604

6. Kamgno J, Nguipdop-Djomo P, Gounoue R, Téjiokem M, Kuesel AC. Effect of two or six doses $800 \mathrm{mg}$ of albendazole every two months on Loa loa microfilaraemia: a double blind, randomized, placebo-controlled trial. PLoS Negl Trop Dis. 2016;10:e0004492. http://dx.doi.org/10.1371/journal.pntd.0004492

7. Tabi TE, Befidi-Mengue R, Nutman TB, Horton J, Folefack A, Pensia E, et al. Human loiasis in a Cameroonian village: a doubleblind, placebo-controlled, crossover clinical trial of a three-day albendazole regimen. Am J Trop Med Hyg. 2004;71:211-5. http://dx.doi.org/10.4269/ajtmh.2004.71.211

8. Klion AD, Horton J, Nutman TB. Albendazole therapy for loiasis refractory to diethylcarbamazine treatment. Clin Infect Dis. 1999;29:680-2. http://dx.doi.org/10.1086/598654

9. Arrey-Agbor DB, Nana-Djeunga HC, Mogoung-Wafo AE, Mafo M, Danwe C, Kamgno J. Case report: probable case of spontaneous encephalopathy due to loiasis and dramatic reduction of Loa loa microfilariaemia with prolonged repeated courses of albendazole. Am J Trop Med Hyg. 2018;99:112-5. http://dx.doi.org/10.4269/ajtmh.17-0664

10. Antinori S, Schifanella L, Million M, Galimberti L, Ferraris L, Mandia L, et al. Imported Loa loa filariasis: three cases and a review of cases reported in non-endemic countries in the past 25 years. Int J Infect Dis. 2012;16:e649-62.

11. Klion AD, Massougbodji A, Horton J, Ekoué S, Lanmasso T, Ahouissou NL, et al. Albendazole in human loiasis: results of a double-blind, placebo-controlled trial. J Infect Dis. 1993;168:2026. http://dx.doi.org/10.1093/infdis/168.1.202

12. Martin-Prevel Y, Cosnefroy JY, Tshipamba P, Ngari P, Chodakewitz JA, Pinder M. Tolerance and efficacy of single highdose ivermectin for the treatment of loiasis. Am J Trop Med Hyg. 1993;48:186-92. http://dx.doi.org/10.4269/ajtmh.1993.48.186

13. Pion SD, Tchatchueng-Mbougua JB, Chesnais CB, Kamgno J, Gardon J, Chippaux JP, et al. Effect of a single standard dose $(150-200 \mu \mathrm{g} / \mathrm{kg})$ of ivermectin on Loa loa microfilaremia: systematic review and meta-analysis. Open Forum Infect Dis. 2019;6:ofz019. http://dx.doi.org/10.1093/ofid/ofz019

14. Gobbi F, Postiglione C, Angheben A, Marocco S, Monteiro G, Buonfrate D, et al. Imported loiasis in Italy: an analysis of 100 cases. Travel Med Infect Dis. 2014;12(6 Pt B):713-7. http://dx.doi.org/10.1016/j.tmaid.2014.07.004

15. Kamgno J, Pion SD, Chesnais CB, Bakalar MH, D'Ambrosio MV, Mackenzie CD, et al. A test-and-not-treat strategy for onchocerciasis in Loa loa-endemic areas. N Engl J Med. 2017;377:2044-52. http://dx.doi.org/10.1056/NEJMoa1705026

16. Gobbi F, Bottieau E, Bouchaud O, Buonfrate D, Salvador F, Rojo-Marcos G, et al. Comparison of different drug regimens for the treatment of loiasis - a TropNet retrospective study. PLoS Negl Trop Dis. 2018;12:e0006917. http://dx.doi.org/10.1371/ journal.pntd.0006917

Address for correspondence: Federico Gobbi, IRCCS Sacro Cuore Don Calabria Hospital, Department of Infectious-Tropical Diseases and Microbiology (DITM), Via Sempreboni 5, 37024 Negrar (Verona), Italy; email: federico.gobbi@sacrocuore.it 